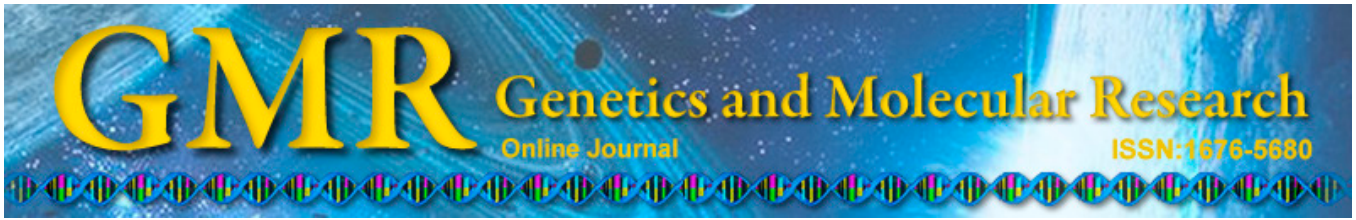

\title{
Association of CD14 C159T polymorphism with atopic asthma susceptibility in children from Southeastern China: a case-control study
}

\author{
Y.N. Zhang ${ }^{1 *}$, Y.J. Li ${ }^{1 *}$, H. Li ${ }^{1}$, H. Zhou ${ }^{2}$ and X.J. Shao ${ }^{2}$ \\ ${ }^{1}$ Department of Clinical Laboratory, The Taixing People's Hospital, Taixing, \\ Jiangsu, China \\ ${ }^{2}$ Department of Clinical Laboratory, Affiliated Children's Hospital, \\ Soochow University, Suzhou, Jiangsu, China \\ *These authors contributed equally to this study. \\ Corresponding author: X.J. Shao \\ E-mail: xuejunshao2014@163.com
}

Genet. Mol. Res. 14 (2): 4311-4317 (2015)

Received April 25, 2014

Accepted October 6, 2014

Published April 30, 2015

DOI http://dx.doi.org/10.4238/2015.April.30.3

\begin{abstract}
CD14 is involved in primary immune and inflammatory responses. The $-159 \mathrm{C} / \mathrm{T}$ variation in the $\mathrm{CD} 14$ gene plays an important role in regulating CD14 expression and has been associated with the susceptibility to various diseases, including allergies. In this study, we examined the association between the C-159T polymorphism and atopic asthma susceptibility in children from Southeastern China. The study population included 746 unrelated children of Chinese Han nationality (362 patients with atopic asthma and 384 healthy controls). CD14 gene polymorphisms were identified by direct sequencing of polymerase chain reaction products. Total immunoglobulin E (IgE) levels in human serum samples were determined using an enzymelinked immunosorbent assay. Individuals carrying the TT genotypes for rs2569190 were significantly associated with an increased risk of atopic asthma compared with those carrying the wild-type homozygous CC genotypes [adjusted odds ratio (OR) by gender and age, from 1.075-
\end{abstract}


2.398, $\mathrm{P}=0.025]$. Total serum IgE levels in TT genotype carriers were significantly higher than those in $\mathrm{CC}$ genotype carriers in atopic asthma patients $(286.3 \pm 161.5 \mathrm{IU} / \mathrm{mL}$ vs $248.3 \pm 147.8 \mathrm{IU} / \mathrm{mL})$. Our data suggest that the CD14 TT genotype may be a genetic susceptibility marker for atopic asthma in Chinese Han children.

Key words: Atopic asthma; CD14; Polymorphism

\section{INTRODUCTIONS}

Asthma is a chronic disease of the airways characterized by various symptoms such as airway irritation, obstruction, and inflammation (Lemanske and Busse, 2010). Approximately 300 million people worldwide suffer from asthma (Normansell et al., 2014). Asthma is a complex immune disorder whose development is determined by genetic and environmental factors. Although a wide variety of genes have been associated with asthma, most of these associations have not been confirmed in multiple populations, indicating a complex genetic susceptibility pattern.

The human CD14 gene is located on chromosome 5q31.1, is approximately 3900 base pairs, and is present in 2 exons. CD14 is a glycoprotein located on the cell surface and is mainly produced by monocytes, macrophages, and neutrophils (Parajuli et al., 2012). CD14 has been shown to be involved in primary immune and inflammatory responses (Apetoh et al., 2007; Berthet et al., 2012; Guo et al., 2013). Studies have demonstrated that genetic variations in CD14 may change the structure of the CD14 protein and influence CD14-lipopolysaccharide (LPS) interactions (Baldini et al., 1999; Karhukorpi et al., 2002). Thus, an increasing number of studies have examined the relationship between CD14 gene variations and disease susceptibility. It has been reported that the $-159 \mathrm{C} / \mathrm{T}$ variant in the CD14 gene plays an important role in regulating CD14 expression and is associated with the susceptibility to various diseases, including allergies (Sengler et al., 2003; Bakolis et al., 2012; Wang et al., 2012). Previous studies focused on the association between atopic asthma and CD14 gene variations (Kedda et al., 2005; Nishimura et al., 2006; Zhao et al., 2011), but the results are contradictory. These different results may be because of genetic heterogeneity between races. In the Chinese Han population, it is unknown whether the CD14 gene polymorphism is associated with atopic asthma.

In this study, we investigated the frequency of the CD14 C159T polymorphism in patients with atopic asthma and evaluated the association between the polymorphism and susceptibility to atopic asthma in children from Southeastern China.

\section{MATERIAL AND METHODS}

\section{Subjects}

The study population included 746 unrelated children of Chinese Han nationality (362 patients with atopic asthma and 384 healthy controls). Written informed consent was obtained from the parent or guardian of the participants. Our study protocol complied with the guidelines of the 1975 Helsinki Declaration and was approved by the Institutional Review Board of the Affiliated Children's Hospital, Soochow University. All patients were recruited from the 
Affiliated Children's Hospital, Soochow University. The diagnosis of asthma in all subjects was performed by asthma specialists according to previously described criteria (Zhang et al., 2013). The 362 children with asthma ranged from 2-12 years of age and included 199 males and 163 females. Individuals enrolled as control subjects were randomly recruited from a group of individuals who participated in routine checkups. The inclusion criteria of the control group were described previously (Isidoro-García et al., 2005).

\section{Genomic DNA extraction and polymerase chain reaction (PCR) amplification}

From each child, $1 \mathrm{~mL}$ samples of venous blood were obtained and stored in ethylenediaminetetraacetic acid-containing anti-coagulative tubes at $-70^{\circ} \mathrm{C}$. Genomic DNA was extracted from blood samples using a commercial DNA extraction kit (Tiangen Biotech Co., Ltd., Beijing, China) according to the manufacturer protocol. CD14 gene polymorphisms were identified by direct sequencing of PCR products. Primer sequences were as follows: forward: 5'-CACCCACCAGAGAAGGCTTA-3'; reverse 5'-ATCACCTCCCCACCTCTCTT-3'. PCR amplification was carried out in a $20-\mu \mathrm{L}$ reaction volume containing $5.0 \mathrm{ng}$ genomic DNA, $5.0 \mu \mathrm{L} 1 \mathrm{X}$ PCR buffer, $1 \mu \mathrm{L}$ of each primer $(10 \mathrm{pM}), 1.0 \mu \mathrm{L}$ of each dNTP $(4.0 \mathrm{mM}), 4 \mu \mathrm{L}$ $\mathrm{MgCl} 2$, and $0.5 \mu \mathrm{L}$ Taq enzyme $(2.0 \mathrm{U} / \mu \mathrm{L})$. PCR parameters consisted of an initial denaturation at $95^{\circ} \mathrm{C}$ for $15 \mathrm{~min}$, followed by 35 cycles of $95^{\circ} \mathrm{C}$ for $30 \mathrm{~s}, 54^{\circ} \mathrm{C}$ for $1 \mathrm{~min}$, and $65^{\circ} \mathrm{C}$ for $1 \mathrm{~min}$, with a final extension step at $72^{\circ} \mathrm{C}$ for $10 \mathrm{~min}$. The PCR product was purified and sequenced by Shanghai Sangon Biological Engineering Technology and Services Co., Ltd. (Shanghai, China).

\section{Determination of total immunoglobulin $\mathrm{E}$ (IgE) in serum}

The total level of IgE in the human serum samples was determined using an enzymelinked immunosorbent assay (ELISA) using the Immunoglobulin E Human ELISA Kit (Abcam, Cambridge, MA, USA) according to manufacturer instructions.

\section{Statistical analysis}

Statistical analysis was performed using the Statistical Package for the Social Sciences (version 12.0, SPSS Inc., Chicago, IL, USA). We used Pearson's chi-square test to examine the differences in demographic characteristics and compare genotype distributions between cases and controls. Odd ratios (ORs) and 95\% confidence intervals (CIs) were calculated to evaluate the association between CD14 gene variants and the risk of atopic asthma using an unconditional logistic regression model. For all statistical tests, a 2-tailed probability level of $\mathrm{P}<0.05$ was considered to be statistically significant.

\section{RESULTS}

\section{Subject characteristics}

In this study, 362 children with atopic asthma (females: 163, males: 199, median age: 6.6 years) and 315 healthy controls (females: 165 , males: 219 , median age: 6.7 years) were recruited. The demographic characteristics and clinical information of atopic asthma cases and healthy controls are summarized in Table 1. Chi-square tests were used to examine the 
differences between cases and controls. As shown in Table 1, the cases and healthy controls were well matched in terms of age and gender. However, there were more parental asthma and parental atopy cases among patients compared with controls.

\begin{tabular}{|c|c|c|c|c|c|c|c|}
\hline \multirow[t]{2}{*}{ Variable } & & \multirow{2}{*}{$\frac{\text { Case }(\mathrm{N}=362)}{\mathrm{N}}$} & \multirow[b]{2}{*}{$\%$} & \multicolumn{2}{|l|}{ Control $(\mathrm{N}=384)$} & \multirow[t]{2}{*}{$\chi^{2}$} & \multirow[t]{2}{*}{$P$ values } \\
\hline & & & & $\mathrm{N}$ & $\%$ & & \\
\hline \multirow{2}{*}{ Gender } & Female & 163 & 45.0 & 165 & 43.0 & 0.321 & 0.606 \\
\hline & Male & 199 & 55.0 & 219 & 57.0 & & \\
\hline \multirow{3}{*}{ Age (years) } & $2-4$ & 36 & 9.9 & 38 & 9.9 & 0.053 & 0.979 \\
\hline & $4-8$ & 252 & 69.6 & 270 & 70.3 & & \\
\hline & $8-12$ & 74 & 20.4 & 76 & 19.8 & & \\
\hline \multicolumn{7}{|c|}{ Parental asthma } & 0.045 \\
\hline \multirow{3}{*}{ Parental atop } & Yes & 15 & 4.1 & 6 & 1.6 & דo. & \\
\hline & No & 282 & 77.9 & 323 & 84.1 & 4.694 & 0.032 \\
\hline & Yes & 80 & 22.1 & 61 & $\begin{array}{l}0+1 . \\
15.9\end{array}$ & & \\
\hline
\end{tabular}

\section{Distribution of genotypes and alleles of CD14 C159T}

The observed genotype frequencies of rs 2569190 genetic variant sites corresponded to Hardy-Weinberg equilibrium in both asthma cases and controls (cases group: $\chi^{2}=3.001$, $\mathrm{P}=0.083$; control group: $\chi^{2}=0.325, \mathrm{P}=0.568$ ). Atopic asthma patients showed $\mathrm{rs} 2569190$ $\mathrm{CC}, \mathrm{CT}$, and TT genotype frequencies of $27.6,45.0$, and $27.3 \%$, respectively, whereas these frequencies in healthy control subjects were $31.3,49.5$, and $19.3 \%$, respectively. These results showed that frequencies of the TT genotypes of CD14 were significantly higher in atopic asthma patients than in healthy control subjects $\left(\chi^{2}=6.853, \mathrm{P}=0.032\right)$. In addition, the $\mathrm{T}$ allele carrier was significantly higher in atopic asthma patients than in healthy control subjects $\left(\chi^{2}=5.124, \mathrm{P}=0.026\right)($ Table 2$)$.

Table 2. Genotype and allele frequency of the polymorphism rs2569190 in cases and controls.

\begin{tabular}{|c|c|c|c|c|c|}
\hline \multirow[t]{2}{*}{ Groups } & \multicolumn{3}{|c|}{ Genotype frequencies (\%) } & \multicolumn{2}{|c|}{ Allele frequencies $(\%)$} \\
\hline & $\mathrm{CC}$ & CT & TT & $\mathrm{C}$ & $\mathrm{T}$ \\
\hline $\begin{array}{l}\text { Cases }(\mathrm{N}=362) \\
\text { Controls }(\mathrm{N}=384)\end{array}$ & $\begin{array}{c}100(27.6) \\
120(31.3) \\
\chi^{2}=6.853, \mathrm{P}=0.032\end{array}$ & $\begin{array}{l}163(45.0) \\
190(49.5)\end{array}$ & $\begin{array}{l}99(27.3) \\
74(19.3)\end{array}$ & $\begin{aligned} & 363(50.1) \\
& 430(56.0) \\
& \chi^{2}= 5.124, \mathrm{P}=0.026\end{aligned}$ & $\begin{array}{l}361(49.9) \\
338(44.0)\end{array}$ \\
\hline
\end{tabular}

\section{Association between rs2569190 and atopic asthma risk}

Table 3 shows the association between CD14 variant rs2569190 and atopic asthma risk. Individuals carrying the TT genotypes for the rs 2569190 were associated significantly with an increased risk of atopic asthma compared with those carrying the wild-type homozygous CC genotypes (adjusted OR by gender and age, from 1.075$2.398, \mathrm{P}=0.025)$. The risk of atopic asthma was significantly higher among subjects carrying at least one $\mathrm{T}$ allele compared to patients carrying the $\mathrm{C}$ allele $(\mathrm{OR}=1.265$, $95 \% \mathrm{CI}=1.032-1.551, \mathrm{P}=0.026$ ). 
Table 3. Association between rs 1057317 and atopic asthma risk.

\begin{tabular}{llrrrr}
\hline & & Case & Control & OR (95\%CI) & P values \\
\hline Genotype & CC & $100(27.6)$ & $120(31.3)$ & & \\
& CT & $163(45.0)$ & $190(49.5)$ & $1.029(0.734-1.443)$ & 0.931 \\
\multirow{2}{*}{ Allele } & TT & $99(27.3)$ & $74(19.3)$ & $\mathbf{1 . 6 0 5 ( 1 . 0 7 5 - 2 . 3 9 8 )}$ & $\mathbf{0 . 0 2 5}$ \\
& C & $363(50.1)$ & $430(56.0)$ & $\mathbf{1 . 2 6 5 ( 1 . 0 3 2 - 1 . 5 5 1 )}$ & $\mathbf{0 . 0 2 6}$ \\
\hline
\end{tabular}

Bold numbers indicate $\mathrm{P}<0.05$.

\section{Association between rs2569190 and serum total IgE levels}

The ELISA results showed that serum total IgE levels were significantly higher in atopic asthma patients than in healthy control subjects $(268.7 \pm 150.9 \mathrm{IU} / \mathrm{mL} v s 151.3 \pm 77.2$ $\mathrm{IU} / \mathrm{mL}$ ) (Figure 1A). In addition, the serum total IgE levels of TT genotype carriers were significantly higher than those in CC genotype carriers in atopic asthma patients $(286.3 \pm 161.5$ $\mathrm{IU} / \mathrm{mL}$ s $248.3 \pm 147.8 \mathrm{IU} / \mathrm{mL}$ ) (Figure 1B).

A

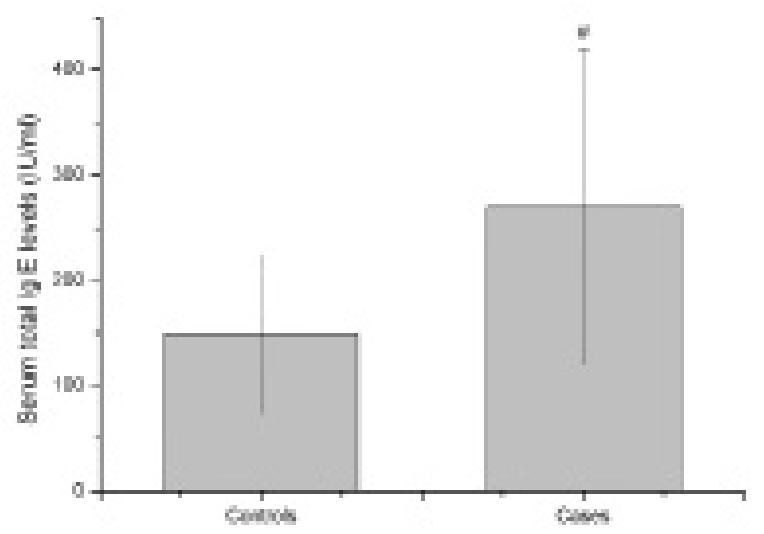

B

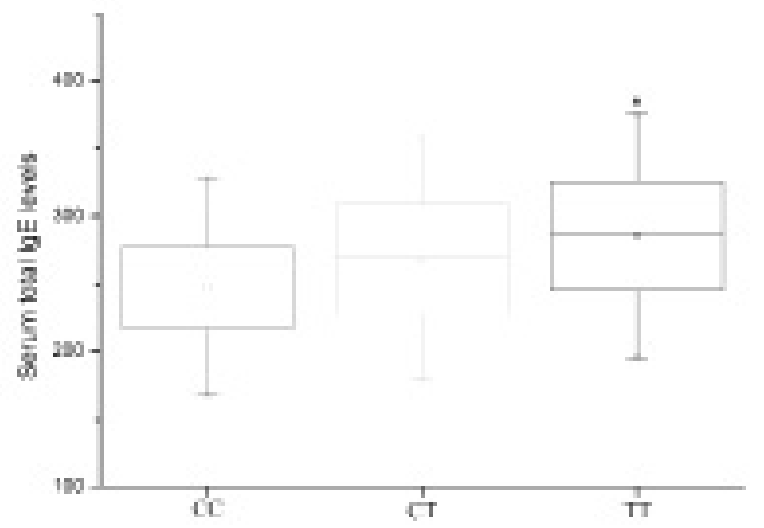

Figure 1. Association between rs2569190 and serum total IgE levels. A. Serum total IgE levels were measured in cases and controls. B. Serum total IgE levels were measured in atopic asthma patients with different genotypes. \# Compared to controls, $\mathrm{P}<0.05 ;$ *Compared to patients with $\mathrm{CC}$ genotype, $\mathrm{P}<0.05$. 


\section{DISCUSSION}

In this study, we examined the association between the CD14 single-nucleotide polymorphism rs2569190 and susceptibility to asthma in Chinese children. All study groups (cases and controls) were from the same geographic and ethnic origin in Southeastern China. We observed a significant association between this polymorphism and asthma in Chinese children. This is the first report describing the association between the CD14 polymorphism and atopic asthma in Chinese children. The results of our study confirm the role of CD14 polymorphisms in asthma development.

CD14, encoded by a single-copy gene located on the cytokine gene cluster on chromosome 5q31.1, is an essential receptor for LPS recognition (Wang et al., 2013). Variants in the promoter region of the $\mathrm{CD} 14$ gene may alter the structure of the $\mathrm{CD} 14$ protein and modulate CD14-LPS interactions. A C-T substitution at base pair 260 of the $5^{\prime}$ flanking region of CD14 -260 (rs2569190, also known as CD14 -159 C/T) is the most widely studied of the CD14 polymorphisms. The rs2569190 single-nucleotide polymorphism has been investigated as a candidate genetic locus in asthma and allergic disease (Pinto et al., 2009). Among skin test-positive atopic children, Baldini et al. (1999) found that compared with subjects carrying the CC and CT genotypes, subjects with the TT genotype showed significantly higher levels of soluble CD14 (sCD14) than either the CC or CT genotype carriers. Several studies demonstrated that CD14 rs2569190 may be associated with asthma. This association has been analyzed in two metaanalyses (Zhang et al., 2011; Zhao and Bracken, 2011). No significant overall association was found between rs 2569190 and asthma. However, when analysis was stratified by atopy, there was a protective effect of the T allele of rs 2569190 in relation to atopic asthma. In the present study, we found that the risk of atopic asthma was significantly higher among subjects carrying at least one $\mathrm{T}$ allele than among patients carrying the $\mathrm{C}$ allele. The difference between our study and other studies may be because of genetic heterogeneity of races.

Most studies have reported that subjects with the TT genotype had higher sCD14 levels than subjects with other genotypes (Kedda et al., 2005; Tan et al., 2006). However, a number of subsequent studies yielded conflicting results regarding the association between CD14 rs2569190 and total serum IgE levels in different populations. Some studies found that the $\mathrm{T}$ allele was associated with a reduced risk of atopy and/or lower IgE levels (Koppelman et al., 2001; Bucková et al., 2003), while other studies found no such association (Leung et al., 2003; Eder et al., 2005), or an increased risk of atopy and higher IgE levels in subjects with the rs2569190 T allele (Jackola et al., 2006; Lachheb et al., 2008). In the present study, we found that the serum total IgE levels of TT genotype carriers were significantly higher than those in CC genotype carriers in atopic asthma patients. Further studies are needed to determine the mechanism behind this observation.

In conclusion, our data suggest that the CD14 TT genotype may be a genetic susceptibility marker for asthma in the Chinese population. To confirm our findings, further case-control or cohort studies with larger sample sizes and in vivo functional evaluations are needed.

\section{REFERENCES}

Apetoh L, Ghiringhelli F, Tesniere A, Obeid M, et al. (2007). Toll-like receptor 4-dependent contribution of the immune system to anticancer chemotherapy and radiotherapy. Nat. Med. 13: 1050-1059.

Bakolis I, Doekes G, Heinrich J, Zock JP, et al. (2012). Respiratory health and endotoxin: associations and modification 
by CD14/-260 genotype. Eur. Respir. J. 39: 573-581.

Baldini M, Lohman IC, Halonen M, Erickson RP, et al. (1999). A polymorphism* in the $5^{\prime}$ flanking region of the CD14 gene is associated with circulating soluble CD14 levels and with total serum immunoglobulin E. Am. J. Respir. Cell. Mol. Biol. 20: 976-983.

Berthet J, Damien P, Hamzeh-Cognasse H, Arthaud CA, et al. (2012). Human platelets can discriminate between various bacterial LPS isoforms via TLR4 signaling and differential cytokine secretion. Clin. Immunol. 145: 189-200.

Bucková D, Hollá LI, Schüller M, Znojil V, et al. (2003). Two CD14 promoter polymorphisms and atopic phenotypes in Czech patients with IgE-mediated allergy. Allergy 58: 1023-1026.

Eder W, Klimecki W, Yu L, von Mutius E, et al. (2005). Opposite effects of CD 14/-260 on serum IgE levels in children raised in different environments. J. Allergy Clin. Immunol. 116: 601-607.

Guo S, Al-Sadi R, Said HM and Ma TY (2013). Lipopolysaccharide causes an increase in intestinal tight junction permeability in vitro and in vivo by inducing enterocyte membrane expression and localization of TLR-4 and CD14. Am. J. Pathol. 182: 375-387.

Isidoro-García M, Dávila I, Laffond E, Moreno E, et al. (2005). Interleukin-4 (IL4) and interleukin-4 receptor (IL4RA) polymorphisms in asthma: a case control study. Clin. Mol. Allergy 3: 15.

Jackola DR, Basu S, Liebeler CL, Willaert R, et al. (2006). CD14 promoter polymorphisms in atopic families: implications for modulated allergen-specific immunoglobulin E and G1 responses. Int. Arch. Allergy Immunol. 139: 217-224.

Karhukorpi J, Yan Y, Niemela S, Valtonen J, et al. (2002). Effect of CD14 promoter polymorphism and H. pylori infection and its clinical outcomes on circulating CD14. Clin. Exp. Immunol. 128: 326-332.

Kedda MA, Lose F, Duffy D, Bell E, et al. (2005). The CD14 C-159T polymorphism is not associated with asthma or asthma severity in an Australian adult population. Thorax 60: 211-214.

Koppelman GH, Reijmerink NE, Colin Stine O, Howard TD, et al. (2001). Association of a promoter polymorphism of the CD14 gene and atopy. Am. J. Respir. Crit. Care Med. 163: 965-969.

Lachheb J, Dhifallah IB, Chelbi H, Hamzaoui K, et al. (2008). Toll-like receptors and CD14 genes polymorphisms and susceptibility to asthma in Tunisian children. Tissue Antigens 71: 417-425.

Lemanske RF Jr and Busse WW (2010). Asthma: clinical expression and molecular mechanisms. J. Allergy Clin. Immunol. 125: S95-S102.

Leung TF, Tang NL, Sung YM, Li AM, et al. (2003). The C-159T polymorphism in the CD14 promoter is associated with serum total IgE concentration in atopic Chinese children. Pediatr. Allergy Immunol. 14: 255-260.

Nishimura F, Shibasaki M, Ichikawa K, Arinami T, et al. (2006). Failure to find an association between CD14-159C/T polymorphism and asthma: a family-based association test and meta-analysis. Allergol. Int. 55: 55-58.

Normansell R, Walker S, Milan SJ, Walters EH, et al. (2014). Omalizumab for asthma in adults and children. Cochrane Database Syst. Rev. 1: CD003559.

Parajuli B, Sonobe Y, Kawanokuchi J, Doi Y, et al. (2012). GM-CSF increases LPS-induced production of proinflammatory mediators via upregulation of TLR4 and CD14 in murine microglia. J. Neuroinflammation 9: 268.

Pinto LA, Stein RT and Ribeiro JD (2009). Genetic associations with asthma and virus-induced wheezing: a systematic review. J. Bras. Pneumol. 35: 1220-1226.

Sengler C, Haider A, Sommerfeld C, Lau S, et al. (2003). Evaluation of the CD14 C-159 T polymorphism in the German Multicenter Allergy Study cohort. Clin. Exp. Allergy 33: 166-169.

Tan CY, Chen YL, Wu LS, Liu CF, et al. (2006). Association of CD14 promoter polymorphisms and soluble CD14 levels in mite allergen sensitization of children in Taiwan. J. Hum. Genet. 51: 59-67.

Wang Z, Hu J, Fan R, Zhou J, et al. (2012). Association between CD14 gene C-260T polymorphism and inflammatory bowel disease: a meta-analysis. PLoS One 7: e45144.

Wang Z, Sundy JS, Foss CM, Barnhart HX, et al. (2013). Racial differences in the association of CD14 polymorphisms with serum total IgE levels and allergen skin test reactivity. J. Asthma Allergy 6: 81-92.

Zhang Y, Tian C, Zhang J, Li X, et al. (2011). The -159C/T polymorphism in the CD14 gene and the risk of asthma: a meta-analysis. Immunogenetics 63: 23-32.

Zhang Y, Han Y, Dong L, Yu H, et al. (2013). Genetic variation of ITGB3 is associated with asthma in Chinese Han children. PLoS One 8: e56914.

Zhao L and Bracken MB (2011). Association of CD14 -260 (-159) C > T and asthma: a systematic review and metaanalysis. BMC Med. Genet. 12: 93. 